\title{
Effect of Organizational Culture of Nursing Care Workers on their Innovative Behavior: Focusing on the Mediating Effect of Knowledge Sharing
}

\author{
In Sook Kim ${ }^{1}$, Sun Hee Park ${ }^{2}$ \\ ${ }^{1}$ Professor, Department of social welfare \& Business Administration, Tongmyong University, Korea, \\ ts3260@hanmail.net \\ ${ }^{2}$ Professor, Department of social welfare \& Business Administration, Tongmyong University, Korea, \\ park_0824@hanmail.net \\ Corresponding author: Sun Hee Park
}

\begin{abstract}
This study is aimed to analyze the mediating effect of knowledge sharing on relationships between the organizational culture and innovative behavior of nursing care providers, and providing implications for improving the quality of services by virtue of innovative behaviors of those providers. To achieve the research objectives, the study conducted a questionnaire survey of care workers for nursing homes located in Busan and Daegu from August 10 to August 31, 2020. Among pieces of the questionnaire form filled out by the participants that were collected through the survey, the study analyzed 335 ones in total using SPSS 21.0 and AMOS 23.0 Programs. The findings of this research can be briefly described as follows. First, care workers serving at nursing homes showed significant differences in relation-oriented culture, innovation-oriented culture, knowledge sharing and innovative behavior level by their demographic characteristics. Second, it was found that organizational culture of those workers, except for innovation-oriented culture, had a significant effect on their knowledge sharing. Third, it was also found that the stronger the organizational culture was, the higher the innovative behavior level was. Fourth, it was discovered that knowledge sharing between care workers had a significant influence on their innovation behavior. And fifth, the knowledge sharing was found having a partially mediating impact on relationships between care workers' organizational culture and innovative behavior. When these findings are taken into consideration, this study is intended to provide important implications for higher-quality services from care workers since it turned out that improvement in the organizational culture and knowledge sharing of professional care providers can contribute to strengthening their innovative behaviors.
\end{abstract}

Keywords: Care Workers, Organizational Culture, Behavior, Mediating Effect, Knowledge, Sharing

\section{Introduction}

In 2017 , the proportion of the elderly aged 65 and over to the total population exceeded $14.2 \%$, and Korea entered an aged society. It is predicted that the demand for long-term care will increase in the future due to the active increase of women's participation in socioeconomic activities and the decrease in the awareness of family support for the elderly[1][2]. Since 2008, along with the implementation of the long-term care insurance system for the elderly in Korea, the national qualification system for Care Workers has been implemented in accordance with Article 39-2 of the Elderly Welfare Act to provide

Received: July 29, 2021; $1^{\text {st }}$ Review Result: September 18, 2021; $2^{\text {nd }}$ Review Result: November 1, 2021 Accepted: November 30, 2021 
professional services such as daily life support and emotional support. According to the National Health Insurance Corporation (2020), as of the end of 2019, 93.4\% (377,726 people) of professionals who provided home services were dispatched to homes of beneficiaries, and $76.7 \%$ ( 73,082 people) of those who provided care services at nursing homes[3]. Care Workers are the core of long-term care services and can be said to be professional workers. However, in the various tasks of nursing care workers, the intention to change jobs is high due to the poor working environment and job such as long hours, low wages, and fatigue and stress from emotional labor and physical support activities due to direct care[4-6]. Therefore, prior research on nursing care workers is focused on job burnout, job environment and job satisfaction, job stress and professionalism, job characteristics, empowerment, emotional labor, etc. the current situation[7]. This study was conducted by combining theories of different disciplines to study organizational culture, that is, knowledge sharing and innovative behavior among Care Workers, rather than the role of Care Workers. If organizational culture is an external factor to achieve the goals of a long-term care institution for the elderly, it will be the caregiver, an internal element of the long-term care institution, that can improve the quality of service[8]. Therefore, since the organizational culture of nursing care workers is an important factor that can promote innovative behavior, the researchers will examine the organizational culture first, then the innovation behavior and knowledge sharing. Therefore, this study intends to provide important implications for the provision of professional long-term care services by revealing the relationship between the organizational culture, knowledge sharing, and innovative behavior of Care Workers in long-term care facilities for the elderly.

\section{Contents}

\subsection{Theoretical Background}

Organizational culture refers to the beliefs, values, consciousness, and code of conduct shared by a large number of members within a specific organization as a whole, and was developed to solve problems that occur in the process of adapting to the external environment and integrating internally in the organization[9]. In innovation behavior, creative knowledge sharing that helps members of an organization achieve their job or organizational performance is divided into knowledge collection and knowledge donation approaches [10][11]. It is the act of transferring the knowledge of other members to the [12-15]. With this definition, the preceding studies are as follows. Regarding the relationship between organizational culture and innovation behavior, Eskiler et al. (2016) stated that organizational culture can strengthen organizational performance through support, encouragement, and organization of organizational members' innovative behavior in the relationship between organizational culture and innovation behavior[16]. Kwon Joong-saeng (2011), Jin Yun-hee (2016), Cho Il-hyeong et al. (2018) show that organizational culture has a positive effect on the innovation behavior of organizational members. can be considered as a key factor for [17-19]. According to Park Tae-ho (2002), the relationship between organizational culture and knowledge sharing depends on how effectively the value of knowledge is shared, and emphasizes that it depends on the internal culture of the organization[20]. Ruggles (1998) said that organizational value and culture are prerequisites for the activation of knowledge sharing among members[21], and a number of previous studies confirmed a significant influence relationship between organizational culture and knowledge sharing [22-26]. In the relationship between knowledge sharing and innovation behavior, Fiol (1991) asserts that it is important to foster a sense of community in order to induce members' innovative behavior, and proves that knowledge sharing has an influence relationship with innovative behavior[23]. In a study by Lee Geum-shim (2017) and Lim Jeong-geun (2016), it was also found that knowledge sharing had a significant positive effect on innovation behavior[27][28]. And in the study that proved that 
knowledge sharing had a significant influence on innovative performance, it was found that sharing and exchanging knowledge among organizational members had a significant effect on innovative thinking and behavior, innovative performance, and management performance[27][29]. In this study, based on previous studies, organizational culture is defined as common values, beliefs, thinking styles, decision-making, work performance attitudes and behaviors shared by members of an organization. We intend to apply four organizational culture types: innovation-oriented culture, relationship-oriented culture, task-oriented culture, and hierarchy-oriented culture[30]. Innovation behavior is defined as developing, promoting, and realizing job-related creative ideas at the job site, and we intend to apply Janssen's (2000) type of innovation behavior. It can be seen that knowledge sharing is an important resource of an organization and a source of competitiveness[31]. In this context, the importance of knowledge sharing is recognized and applied to this study.

\subsection{Research Method}

\subsubsection{Research Subject and Analysis Method}

The subjects of this study were collected from 335 Care Workers in Daegu and Busan area, 95.7\% of questionnaires collected from August 10 to August 31, 2020. Structural equation model was used for the analysis method. In addition, the t-test and one-way ANOVA were performed to verify the differences according to the respondents' gender, age, marital status, educational background, and length of service on organizational culture, knowledge sharing, and innovation behavior.

\subsubsection{Research Model and Research Hypothesis}

The purpose of this study is to investigate the mediating effect of knowledge sharing on the relationship between organizational culture and innovative behavior of Care Workers in nursing care facilities. Previous studies reported the results that organizational culture affects knowledge sharing and innovation behavior, and that knowledge sharing affects innovation behavior[27]. Based on these results, knowledge sharing is a mediator between organizational culture and innovation behavior. It can be assumed that it will play a role. Therefore, in this study, the following research model and hypothesis were established [Fig. 1].

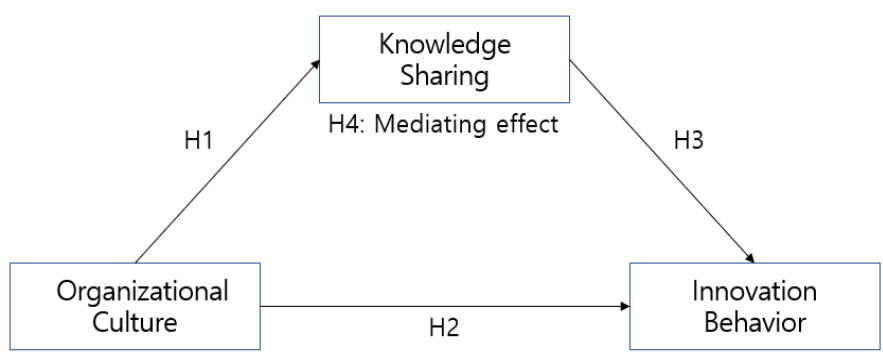

[Fig. 1] Research Model

H1. Organizational culture will have a significant effect on knowledge sharing.

H2. Organizational culture will have a significant effect on innovation behavior.

H3. Knowledge sharing will have a significant effect on innovation behavior.

H4. Knowledge sharing will play a mediating role in mediating the relationship between organizational culture and innovation behavior.H1. Organizational culture will have a significant effect on knowledge sharing.

\subsubsection{Measuring Tools}


Organizational culture was measured using the organizational culture scale used in the study of Lee (2011) based on the theory of Kimberly and Quinn (1984)[32][33]. As a result of deriving Cronbach's $\alpha$ value to verify the reliability of the organizational culture, the total of 20 items was 0.898 for the overall organizational culture, 0.866 for the innovation-oriented culture, a sub-factor of the organizational culture, 0.778 for the relationship-oriented culture, and 0.778 for the task-oriented culture. 0.807 and hierarchical culture were 0.875 . Knowledge sharing was based on the study of Van Den Hooff and De Ridder (2004), and the scale used in the study of Kim Se-won (2019) was used[10][34]. As a result of deriving Cronbach's $\alpha$ value to verify the reliability of knowledge sharing, the total of knowledge sharing was 0.879 , the sub-factor knowledge contribution was 0.879 , and knowledge acquisition was 0.826 . For innovation behavior, the scale used in the study of Wang Byeong-cheol (2020) was used based on the measurement scale of Janssen (2000)[35][36]. There are a total of 5 items, and as a result of deriving Cronbach's $\alpha$ value to verify the reliability of innovation behavior, it was found to be 0.775 .

\subsection{Results}

\subsubsection{Demographic Characteristics of the Research Subjects}

In terms of demographic characteristics, the subjects of this study were male $10.7 \%$ (36 people) and female $89.3 \%$ (299), and by age, 30s $20.0 \%$ (67 people), $40 \mathrm{~s} 23.9 \%$ ( 80 people), $36.1 \%$ (121 people) in their $50 \mathrm{~s}$ and $20.0 \%$ (67 people) in their $60 \mathrm{~s}$ or older. As for marital status, $36.7 \%$ (123 people) are single, $63.3 \%$ (212 people) are married, and their educational background is less than high school (or attending) 39.7\% (133 people), college graduate 36.7\% (123 people), college graduate $20.0 \%$ ( 67 ), and 3.6\% (12) with graduate school or higher. In terms of service period, less than 1 year $19.1 \%$ (64 people), 1 year to less than 3 years $34.9 \%$ (117 people), 30.1\% to less than 5 years $30.1 \%$ (101 people), 5 years or more $15.8 \%$ (53 people) ) appeared.

\subsubsection{Difference Verification}

The following [Table 1] shows that as a result of post-mortem analysis examining differences in organizational culture according to demographic characteristics of Care Workers.

[Table 1] Difference in Organizational Culture of Care Workers by Demographic Characteristics $(n=335)$

\begin{tabular}{|c|c|c|c|c|c|c|c|}
\hline Category & \multicolumn{2}{|c|}{ Demographic characteristics } & $\mathrm{N}$ & $\mathrm{M}$ & $\mathrm{SD}$ & $t / F$ & Scheffe test \\
\hline \multirow{11}{*}{$\begin{array}{c}\text { Innovation } \\
\text {-oriented culture }\end{array}$} & \multirow{2}{*}{ Sex } & Male & 36 & 3.71 & .563 & \multirow{2}{*}{$2.384 *$} & \multirow{2}{*}{-} \\
\hline & & Female & 299 & 3.95 & .594 & & \\
\hline & \multirow{4}{*}{ Age } & $30 \mathrm{~s}(\mathrm{a})$ & 67 & 3.91 & .567 & \multirow{4}{*}{$3.801 *$} & \multirow{4}{*}{$a>c$} \\
\hline & & $40 \mathrm{~s}(\mathrm{~b})$ & 80 & 3.77 & .586 & & \\
\hline & & $50 \mathrm{~s}(\mathrm{c})$ & 121 & 3.62 & .557 & & \\
\hline & & $60 \mathrm{~s}(\mathrm{~d})$ & 67 & 3.75 & .543 & & \\
\hline & \multirow{2}{*}{ Marital status } & Unmarried & 123 & 3.84 & .532 & \multirow{2}{*}{$2.479^{*}$} & \multirow{2}{*}{ - } \\
\hline & & Married & 212 & 3.68 & .585 & & \\
\hline & \multirow{3}{*}{ Education } & High school(a) & 133 & 3.76 & .522 & \multirow{3}{*}{$3.010^{*}$} & \multirow{3}{*}{-} \\
\hline & & College(b) & 123 & 3.63 & .596 & & \\
\hline & & University(c) & 67 & 3.87 & .563 & & \\
\hline
\end{tabular}




\begin{tabular}{|c|c|c|c|c|c|c|c|}
\hline & & Grad school(d) & 12 & 3.90 & .711 & & \\
\hline & \multirow{4}{*}{$\begin{array}{l}\text { Duration of } \\
\text { working }\end{array}$} & < 1 year(a) & 132 & 4.07 & .803 & \multirow{4}{*}{$7.463 * * *$} & \multirow{4}{*}{ - } \\
\hline & & $<3$ years $(\mathrm{b})$ & 277 & 4.21 & .809 & & \\
\hline & & $<5$ years(c) & 79 & 4.49 & .586 & & \\
\hline & & $\geq 5$ years $(d)$ & 132 & 3.85 & .892 & & \\
\hline \multirow{16}{*}{$\begin{array}{c}\text { Relation } \\
\text {-oriented culture }\end{array}$} & \multirow{2}{*}{ Sex } & Male & 36 & 3.57 & .573 & \multirow{2}{*}{$3.856^{* * *}$} & \multirow{2}{*}{ - } \\
\hline & & Female & 299 & 3.96 & .604 & & \\
\hline & \multirow{4}{*}{ Age } & $30 \mathrm{~s}(\mathrm{a})$ & 67 & 3.74 & .585 & \multirow{4}{*}{$3.455^{*}$} & \multirow{4}{*}{$a>c$} \\
\hline & & $40 \mathrm{~s}(\mathrm{~b})$ & 80 & 3.65 & .619 & & \\
\hline & & $50 \mathrm{~s}(\mathrm{c})$ & 121 & 3.48 & .580 & & \\
\hline & & $60 \mathrm{~s}(\mathrm{~d})$ & 67 & 3.67 & .531 & & \\
\hline & \multirow{2}{*}{ Marital status } & Unmarried & 123 & 3.72 & .545 & \multirow{2}{*}{$2.488^{*}$} & \multirow{2}{*}{-} \\
\hline & & Married & 212 & 3.55 & .604 & & \\
\hline & \multirow{4}{*}{ Education } & High school(a) & 133 & 3.68 & .530 & \multirow{4}{*}{$5.141 * *$} & \multirow{4}{*}{$\mathrm{a}, \mathrm{c}>\mathrm{b}$} \\
\hline & & College(b) & 123 & 3.45 & .650 & & \\
\hline & & University(c) & 67 & 3.75 & .483 & & \\
\hline & & Grad school(d) & 12 & 3.70 & .751 & & \\
\hline & \multirow{4}{*}{$\begin{array}{l}\text { Duration of } \\
\text { working }\end{array}$} & < 1 year(a) & 132 & 3.50 & .593 & \multirow{4}{*}{1.010} & \multirow{4}{*}{-} \\
\hline & & $<3$ years(b) & 277 & 3.64 & .618 & & \\
\hline & & $<5$ years $(\mathrm{c})$ & 79 & 3.64 & .579 & & \\
\hline & & $\geq 5$ years $(d)$ & 132 & 3.63 & .526 & & \\
\hline \multirow{16}{*}{ Task-oriented culture } & \multirow{2}{*}{ Sex } & Male & 36 & 3.10 & .654 & \multirow{2}{*}{.819} & \multirow{2}{*}{ - } \\
\hline & & Female & 299 & 3.20 & .766 & & \\
\hline & \multirow{4}{*}{ Age } & $30 \mathrm{~s}(\mathrm{a})$ & 67 & 3.03 & .732 & \multirow{4}{*}{.878} & \multirow{4}{*}{-} \\
\hline & & $40 \mathrm{~s}(\mathrm{~b})$ & 80 & 3.08 & .698 & & \\
\hline & & $50 \mathrm{~s}(\mathrm{c})$ & 121 & 3.19 & .578 & & \\
\hline & & $60 \mathrm{~s}(\mathrm{~d})$ & 67 & 3.10 & .710 & & \\
\hline & & Unmarried & 123 & 3.07 & .731 & & \\
\hline & IVtar Itar blatus & Married & 212 & 3.14 & .626 & ה & \\
\hline & & High school(a) & 133 & 3.14 & .641 & & \\
\hline & & College(b) & 123 & 3.10 & .693 & & \\
\hline & Lutudion & University(c) & 67 & 3.06 & .698 & 沙 & - \\
\hline & & Grad school(d) & 12 & 3.22 & .508 & & \\
\hline & & < 1 year(a) & 132 & 3.17 & .641 & & \\
\hline & Duration of & $<3$ years $(\mathrm{b})$ & 277 & 3.08 & .716 & & \\
\hline & working & $<5$ years $(\mathrm{c})$ & 79 & 3.14 & .674 & .404 & - \\
\hline & & $\geq 5$ years $(\mathrm{d})$ & 132 & 3.07 & .575 & & \\
\hline Hierarchy & $\mathrm{S}=\mathrm{g}$ & Male & 36 & 3.58 & .648 & 1702 & \\
\hline -oriented culture & $\operatorname{Sex}$ & Female & 299 & 3.78 & .547 & 1.193 & - \\
\hline
\end{tabular}




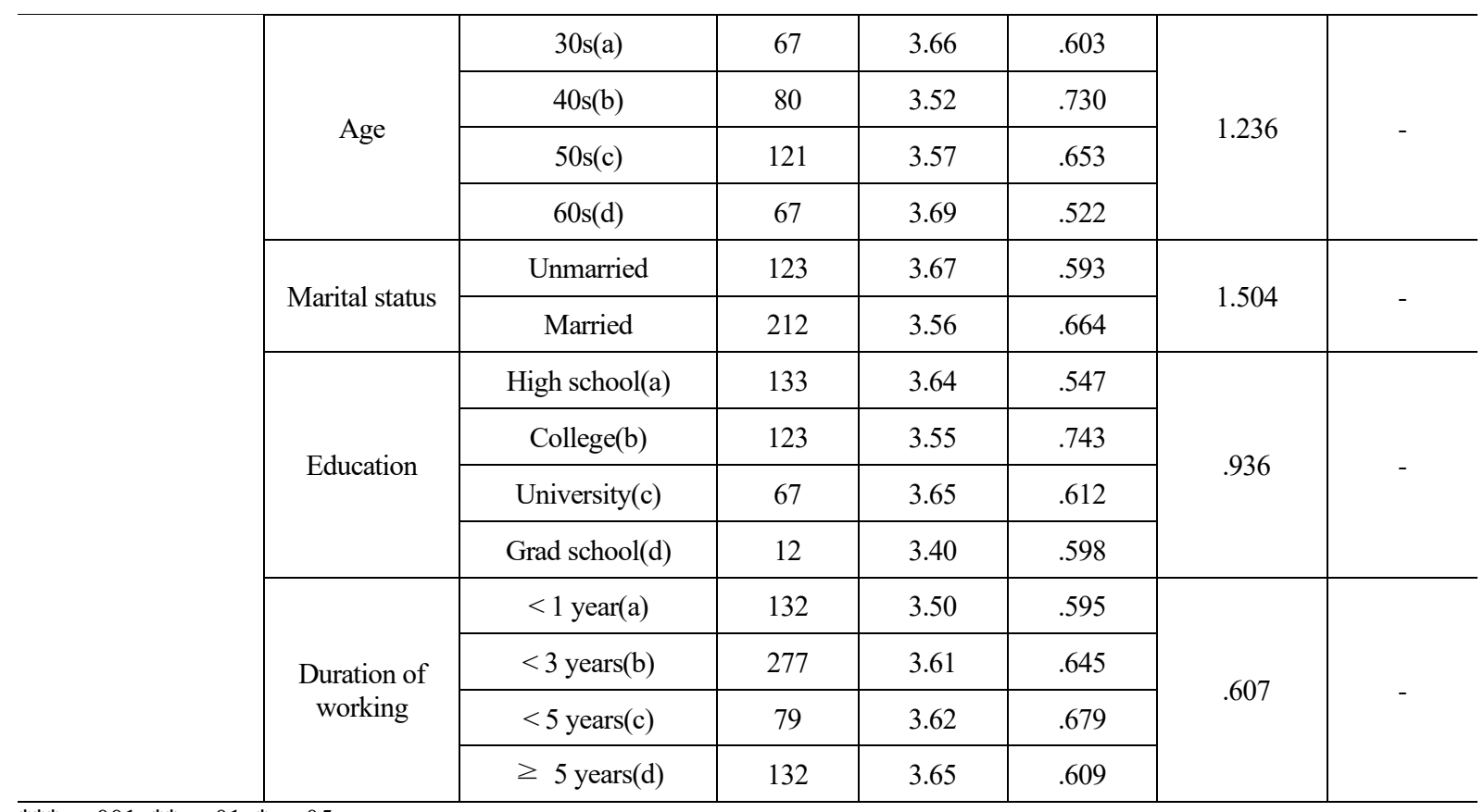

$* * * \mathrm{p}<.001, * * \mathrm{p}<.01, * \mathrm{p}<.05$

The following [Table 2] shows that as a result of a post-hoc analysis examining the difference in knowledge sharing according to demographic characteristics of care workers.

[Table 2] Difference in Care Workers' Knowledge Sharing by Demographic Characteristics $(n=335)$

\begin{tabular}{|c|c|c|c|c|c|c|}
\hline \multicolumn{2}{|c|}{ Demographic characteristics } & $\mathrm{N}$ & M & $\mathrm{SD}$ & $\mathrm{t} / \mathrm{F}$ & Scheffe test \\
\hline \multirow{2}{*}{ Sex } & Male & 36 & 3.51 & .499 & \multirow{2}{*}{$2.994 *$} & \multirow{2}{*}{ - } \\
\hline & Female & 299 & 3.78 & .519 & & \\
\hline \multirow{4}{*}{ Age } & $30 \mathrm{~s}(\mathrm{a})$ & 67 & 3.62 & .528 & \multirow{4}{*}{$2.641^{*}$} & \multirow{4}{*}{-} \\
\hline & $40 \mathrm{~s}(\mathrm{~b})$ & 80 & 3.50 & .519 & & \\
\hline & $50 \mathrm{~s}(\mathrm{c})$ & 121 & 3.46 & .498 & & \\
\hline & $60 \mathrm{~s}(\mathrm{~d})$ & 67 & 3.65 & .468 & & \\
\hline \multirow{2}{*}{ Marital status } & Unmarried & 123 & 3.61 & .463 & \multirow{2}{*}{1.772} & \multirow{2}{*}{-} \\
\hline & Married & 212 & 3.50 & .529 & & \\
\hline \multirow{4}{*}{ Education } & High school(a) & 133 & 3.57 & .460 & \multirow{4}{*}{$3.345^{*}$} & \multirow{4}{*}{ - } \\
\hline & College(b) & 123 & 3.44 & .535 & & \\
\hline & University(c) & 67 & 3.64 & .546 & & \\
\hline & Grad school(d) & 12 & 3.71 & .303 & & \\
\hline \multirow{4}{*}{ Duration of working } & $<1$ year(a) & 132 & 3.48 & .464 & \multirow{4}{*}{1.190} & \multirow{4}{*}{-} \\
\hline & $<3$ years $(\mathrm{b})$ & 277 & 3.58 & .523 & & \\
\hline & $<5$ years $(\mathrm{c})$ & 79 & 3.49 & .503 & & \\
\hline & $\geq 5$ years $(\mathrm{d})$ & 132 & 3.61 & .527 & & \\
\hline
\end{tabular}

${ }^{*} \mathrm{p}<.05$

The following [Table3] shows the results of post-hoc analysis verifying the difference in innovative behaviors according to demographic characteristics of care workers. 
[Table 3] Difference in Innovation Behavior by care workers demographic characteristics $(n=335)$

\begin{tabular}{|c|c|c|c|c|c|c|}
\hline \multicolumn{2}{|c|}{ Demographic characteristics } & $\mathrm{N}$ & M & SD & $t / F$ & Scheffe test \\
\hline \multirow{2}{*}{ Sex } & Male & 36 & 3.67 & .585 & \multirow{2}{*}{$3.314^{* *}$} & \multirow{2}{*}{-} \\
\hline & Female & 299 & 4.01 & .548 & & \\
\hline \multirow{4}{*}{ Age } & $30 \mathrm{~s}(\mathrm{a})$ & 67 & 3.88 & .616 & \multirow{4}{*}{$9.330^{* * *}$} & \multirow{4}{*}{$\mathrm{a}, \mathrm{d}>\mathrm{c}$} \\
\hline & $40 \mathrm{~s}(\mathrm{~b})$ & 80 & 3.71 & .559 & & \\
\hline & $50 \mathrm{~s}(\mathrm{c})$ & 121 & 3.51 & .589 & & \\
\hline & $60 \mathrm{~s}(\mathrm{~d})$ & 67 & 3.90 & .491 & & \\
\hline \multirow{2}{*}{ Marital status } & Unmarried & 123 & 3.86 & .543 & \multirow{2}{*}{$3.590 * * *$} & \multirow{2}{*}{ - } \\
\hline & Married & 212 & 3.62 & .600 & & \\
\hline \multirow{4}{*}{ Education } & High school(a) & 133 & 3.77 & .490 & \multirow{4}{*}{$8.798 * * *$} & \multirow{4}{*}{$\mathrm{a}, \mathrm{c}>\mathrm{b}$} \\
\hline & College(b) & 123 & 3.51 & .630 & & \\
\hline & University(c) & 67 & 3.92 & .610 & & \\
\hline & Grad school(d) & 12 & 3.88 & .528 & & \\
\hline \multirow{4}{*}{ Duration of working } & $<1$ year(a) & 132 & 3.59 & .514 & \multirow{4}{*}{1.242} & \multirow{4}{*}{ - } \\
\hline & $<3$ years(b) & 277 & 3.76 & .628 & & \\
\hline & $<5$ years $(\mathrm{c})$ & 79 & 3.72 & .596 & & \\
\hline & $\geq 5$ years(d) & 132 & 3.71 & .573 & & \\
\hline
\end{tabular}

$* * * \mathrm{p}<.001, * * \mathrm{p}<.01$

\subsubsection{Validation and Reliability Verification}

Confirmatory factor analysis was performed for reliability and validity analysis in this study. As a result of the reliability analysis, CR (composite reliability: CR), which is conceptual reliability, and average variance extracted (AVE) (AVE), which is the index of reliability, were found to be above 0.7 and above 0.5 , respectively, which are the standard values, confirming the internal consistency of all measurement tools. did As a result of examining the fit for research model validation, the fitness of fit such as $=578.267, \mathrm{df}=282, \mathrm{GFI}=0.881, \mathrm{AGFI}=0.841, \mathrm{RMR}=0.037, \mathrm{IFI}=0.929, \mathrm{RMSEA}=0.056$ met the recommended level.

\subsubsection{Correlation Analysis}

In this study, correlation analysis was performed on the relationship between organizational culture, knowledge sharing, and innovative behavior of Care Workers, and the results are as follows. As a result of the analysis, the correlation coefficient between the variables was found to be in the absolute range of 0.199 to 0.673 . As a result of the correlation analysis, if the correlation coefficient between the variables is 0.90 or more, it can be said that the two variables are almost identical, raising the possibility of raising the problem of multicollinearity.. However, in this study, although the correlation coefficient was statistically significant, it was found to be less than 0.9 , and kurtosis and skewness did not exceed \pm 2 , indicating that discriminant validity was secured. This study evaluated the conceptual validity and reliability of the measurement items of this study by conducting confirmatory factor analysis, reliability analysis, and correlation analysis. As a result of the analysis, the internal consistency and concentrated validity of all measurement items were established, and the measurement items of this study, except for the items that were removed because rule validity and discriminant validity were also established, can be judged to have sufficient conceptual validity and reliability. 


\subsubsection{Hypothesis Test}

As a result of examining the fitness for the verification of the research model of this study, the fitness of fit $=636.916, \mathrm{df}=283, \mathrm{GFI}=0.870, \mathrm{AGFI}=0.839, \mathrm{RMR}=0.042, \mathrm{IFI}=0.915$, RMSEA $=0.061$ was found to be in line with the recommended level. The result of examining the structural model path coefficients for hypothesis testing. Hypothesis 1, 'Organizational culture will have a significant effect on knowledge sharing,' was partially supported. Hypothesis 2, 'Organizational culture will have a significant effect on innovation behavior,' and Hypothesis 3, 'knowledge sharing is Both hypotheses of 'will have a significant effect on behavior' were supported. Organizational culture that directly affects the knowledge sharing of Care Workers is relation-oriented culture $(\beta=.209, \mathrm{p}<.05)$, innovationoriented culture $(\beta=.232, \mathrm{p}<.01)$, and task-oriented culture $(\beta=.193, \mathrm{p}<.01)$ and hierarchical culture $(\beta=.165, \mathrm{p}<.05)$ were all found to have a direct effect on the innovation behavior of Care Workers, and knowledge sharing of Care Workers had a direct effect on the innovation behavior. was found to be effective $(\beta=.309, \mathrm{p}<.01)$.

In the significance of the direct effect, indirect effect, and total effect of the research model was verified by the bootstrapping method to examine Hypothesis 4. Hypothesis 4, 'In the relationship between organizational culture and innovation behavior, knowledge sharing will play a mediating role' was partially supported. As a result of the analysis, the direct effect of organizational culture on innovation behavior was significant in all organizational culture types $(p<.05)$, and the indirect effect was found in relation-oriented culture, task-oriented culture, and hierarchical-oriented culture except for innovation-oriented culture. It was found to be significant $(\mathrm{p}<.05)$, and the total effect was found to be statistically significant at the significance level $\mathrm{p}<.001$. In other words, the indirect effect of knowledge sharing on innovation behavior was confirmed in organizational culture except for innovation-oriented culture.

In this study, the Sobel-test presented by Baron and Kenny (1986)[37] was conducted to investigate the mediating effect of knowledge sharing on the relationship between organizational culture and innovation behavior, and the analysis results are as follows [Table 4]. As a result of the analysis, the mediating effect of knowledge sharing on innovation behavior was found to have a significant effect in organizational culture except for innovation-oriented culture. All indirect effects were found to be significant, confirming that organizational culture partially mediates knowledge sharing and affects innovation behavior.

[Table 4] Sobel-test Results as to Knowledge Sharing, Relation-oriented Culture \& Innovation Behavior

\begin{tabular}{c|c|c|c|c}
\hline \multirow{2}{*}{ Independent Variable } & \multirow{2}{*}{ Parameter } & Dependant Variable & \multicolumn{2}{|c}{ Sobel-test } \\
\cline { 4 - 5 } & & & Z-value & P \\
\hline Relation-OCa & & & 2.190 & .028 \\
\hline Innovation-OC & \multirow{3}{*}{ Knowledge Sharing } & Innovation Behavior & 1.136 & .256 \\
\cline { 3 - 4 } Task-OC & & 2.440 & .015 \\
\hline Hierarchy-OC & & & 1.982 & .047 \\
\hline
\end{tabular}

a Oriented Culture

\section{Conclusion and Discussion}

This study analyzed the mediating effect of nursing care workers' knowledge sharing on relationships between their organizational culture and innovative behavior, and is intended to provide basic data for improving such behaviors. The conclusion and discussion of this study are as follows.

First, according to demographic characteristics of care workers, women were evaluated to have stronger organizational relationship-oriented culture and innovation-oriented culture, and knowledge 
sharing and they were higher in innovative behavior level. Second, the higher the relationship-oriented culture, task-oriented culture, and hierarchical-oriented culture of nursing homes, the higher the degree of knowledge sharing among Care Workers. This partially complies with the research results of Lee So-jung and Ha Dong-hyun (2013) who found relation-oriented culture and hierarchical-oriented culture has a significant influence on knowledge sharing[38]. Third, it was confirmed that the stronger the organizational culture of nursing care facilities, the higher the level of innovative behaviors of nursing care providers. This is consistent with the results of Choi In-ok et al. (2011) that group (relationship) culture has a significant positive effect on innovation behavior of members[39], and innovation behavior of os asrganizational members is the key to improving organizational performance. There is a need to improve the organizational culture so that the developmental growth of nursing homes is possible by encouraging the innovative behavior of Care Workers. Fourth,it was turned out that the higher knowledge sharing is, the more positive innovation behavior is. This is also supported by Lim Jeong-geun's(2016) research that knowledgesharing jas a significantly positive impact on innovation behavior[40]. Fifth, the mediating effect of knowledge sharing on relationship between the organizational culture of nursing care facilities and the innovation behavior of care workers was investigated to find that the sharing has significantly direct and total effects on the relationship as well as a partially significant indirect effect on it. This indicates that sharing knowledge partially mediates between organizational culture and innovation culture.

Based on the above discussion and conclusion, the following recommendations for further research were made. In the field of long-term care, improvement of organizational culture and knowledge sharing of Care Workers can improve innovative behavior, which can be expected to improve service quality for service recipients using the long-term care system. In the future, in terms of social welfare, capacity building training for Care Workers so that the quality of life of service users can be improved by voluntarily improving creative innovation behavior through knowledge sharing of Care Workers into a healthy organizational culture by strengthening the internal competency of Care Workers. The researchers expect that this study helps realize an opportunity in which care workers are privided educational programs for competency development and improvement.

\section{References}

[1] T. Muir, Measuring social protection for long-term care, OECD Health Working Papers, OECD, (2017), No.93, DOI: http://dx.doi.org/10.1787/a411500a-en

[2] Health at a Glance 2019: OECD Indicators, OECD, (2019), DOI:https://doi.org/10.1787/4dd50c09-en

[3] Long term care insurance statistical yearbook, National Health Insurance Service, Dept. of Bigdata, (2019), pp.764779.

[4] B. O. Hwang, S. J. Lee, A study about job stress that influences turnover intention of the employees of Long-term Care Services for Older Adults by Q-method, Korean Journal of Gerontological Social Welfare, (2012), No.56, pp.165-190, DOI: https://doi.org/10.21194/kjgsw..56.201206.165

[5] Y. M. Lee, S. J. Kim, K. Kim, Factors influencing work-related burnout of nurses and Care Workers in nursing homes, Journal of the Korea Academia-Industrial cooperation Society, (2013), Vol.14, No.4, pp.1755-1764, DOI: https://doi.org/10.5762/KAIS.2013.14.4.1755

[6] H. Y. Lee, K. S. Park, The effect of job stress on turnover intention of the longterm care workers, Health and Social Welfare Review, (2013), Vol.33, No.2, pp.274-298, DOI: https://doi.org/10.15709/hswr.2013.33.2.274

[7] M. J. Kim, N. S. Kim, A study on organizational culture and organizational justice affecting innovative behavior, Korean Review of Corporation Management, (2019), Vol.10, No.1, pp.199-229, DOI: https://doi.org/10.20434/KRICM.2019.02.10.1.199 
Effect of Organizational Culture of Nursing Care Workers on their Innovative Behavior: Focusing on the mediating Effect of Knowledge Sharing

[8] Y. J. Kim, N. Sun, S. J. Park, Impact on the innovation action for job autonomy of caregiver, Asia-Pacific Journal of Business Venturing and Entrepreneurship, (2016), Vol.11, No.3, pp.199-208, DOI: https://doi.org/10.16972/apjbve.11.3.201606.199

[9] W. K. Cho, The effect of GWP organizational culture on organizational commitment: using H company as a case study, Hanyang University of Korea, Master Thesis, (2013)

[10] B. Van Den Hooff, J. A. De Ridder, Knowledge sharing in context: the influence of organizational commitment, communication climate and CMC use on knowledge sharing, Journal of Knowledge Management, (2004), Vol.8, No.6, pp.117-130, DOI: http://dx.doi.org/10.1108/13673270410567675

[11] H. J. Lee, S. Kim, A study on the factors affecting knowledge contribution in the public sector, Journal of the Korean Society for Information Management, (2010), Vol.27, No.3, pp.169-187, DOI: https://doi.org/10.3743/ KOSIM.2010.27.3.169

[12] G. Kim, The key factors affecting successful knowledge transfer in public officials, Korean Public Administration Review, (2004), Vol.38, No.1, pp.45-68, UCI: G704-000298.2004.38.1.003

[13] Y. H. Fang, C. M. Chiu, In justice we trust: exploring knowledge-sharing continuance intentions in virtual communities of practice, Computers in Human Behavior, (2010), Vol.26, No.2, pp.235-246, DOI: http://dx.doi.org/ 10.1016/j.chb.2009.09.005

[14] T. Kostova, Transnational transfer of strategic organizational practices: a contextual perspective, Academy of Management Review, (1999), Vol.24, No.2, pp.308-324, DOI: http://dx.doi.org/10.2307/259084

[15] S. Watson, K. Hewett, A multi-theoretical model of knowledge transfer in organizations: determinants of knowledge contribution and knowledge reuse, Journal of Management Studies, (2006), Vol.43, No.2, pp.141-173, DOI: http://dx.doi.org/10.1111/j.1467-6486.2006.00586.x

[16] E. Eskiler, S. Ekici, F. Soyer, I. Sari, The relationship between organizational culture and innovative work behavior for sports services in tourism enterprises, Physical Culture and Sport. Studies and Research, (2016), Vol.69, No.1, pp.53-64, DOI: http://dx.doi.org/10.1515/pcssr-2016-0007

[17] J. Kwon, The influence of innovative organization culture to human resource innovation and organizational commitment, Journal of Business Research, (2011), Vol.26, No.1, pp.153-182, DOI: https://doi.org/ 10.22903/jbr.2011.26.1.153

[18] Y. Jin, Effects of organizational culture perception on innovative work behavior: mediating effect of organization support perception, The Journal of Policy Development, (2016), Vol.16, No.2, pp.93-119, DOI: https://doi/org/10.35224/kapd.2016.16.2.004

[19] I. Cho, I. Jeon, K. Chae, A study on the influence of organizational culture on the innovation behavior: the results of a survey in cultural heritage administration, Journal of Government and Policy, (2018), Vol.10, No.2, pp.5-24, UCI: I410-ECN-0102-2018-300-004058102

[20] T. H. Park, The influence of knowledge sharing and its antecedent factors on innovative behavior, Kyungsung University, Doctoral Dissertation, (2002)

[21] R. Ruggles, The state of the notion: knowledge management in practice, California Management Review, (1998), Vol.40, No.3, pp.80-89, DOI: http://dx.doi.org/10.2307/41165944

[22] G. D. Bhatt, Knowledge management in organizations: examining the interaction between technologies, techniques, and people, Journal of Knowledge Management, (2001), Vol.5, No.1, pp.68-75, DOI: http://dx.doi.org/10.1108/ 13673270110384419

[23] M. Fiol, Managing culture as a competitive resource: an identity-based view of sustainable competitive advantage, Journal of Management, (1991), Vol.17, No.1, pp.191-211, DOI: http://dx.doi.org/10.1177/014920639101700112

[24] E. H. Schein, P. A. Schein, Organizational culture and leadership, John Wiley \& Sons, pp.416, (2016)

[25] S. J. Lee, D. H. Ha, Effects of organizational culture on knowledge sharing and business performance, Journal of the Aviation Management Society of Korea, (2013), Vol.11, No.5, pp.19-40, UCI: G704-001900.2013.11.5.002 
[26] S. S. Kim, A study on the relationship among success factors of knowledge management, knowledge sharing, and organizational performance, Journal of Finance \& Knowledge Studies, (2005), Vol.3, No.1, pp.255-282, UCI(KEPA): I410-ECN-0102-2009-320-001610409

[27] G. S. Lee, The effect of individual creativity and perception of value innovation culture on innovation performance and business outcome: the roles of mediating innovative behavior and knowledge sharing, Konyang University, Doctoral Dissertation, (2017)

[28] Z. G. Lin, The effect of professor perceived organization justice, organization trust and knowledge sharing on innovation behavior in China sports university, Keimyung University, Doctoral Dissertation, (2016)

[29] O. K. Kwon, Influence of environmental factors, competitiveness of corporate culture of and knowledge sharing upon innovativeness and business performance, National University of Korea, Doctoral Dissertation, (2008)

[30] K. S. Cameron, R. E. Quinn, Diagnosing and changing organizational culture: based on the competing values framework, Addison Wesley, p.288, (1999)

[31] W. C. Zhang, The effect of external focus culture and knowledge sharing on innovative behavior: focused on moderating effect of Korea and China, Gachon University of Korea, Doctoral Dissertation, (2019)

[32] J. R. Kimberly, R. E. Quinn, Managing organizational transitions, R.D. Irwin, p.322, (1984)

[33] S. Y. Lee, The effects of the types of organizational culture of long-term care facilities on burnout: focused on the mediating effect of job satisfaction and organizational commitment, Daegu University, Doctoral Dissertation, (2011)

[34] S. E. Kim, Effect of Organizational Culture and Knowledge Sharing on Organizational Commitment: Centering on Dental Medical Institution, Kyunghee University, Master Thesis, (2019).

[35] O. Janssen, Job demands, perceptions of effort-reward fairness and innovative work behaviour, Journal of Occupational and Organizational Psychology, (2000), Vol.73, No.3, pp.287-302, DOI: https://doi.org/ $10.1348 / 096317900167038$

[36] B. Z. Wang, The Effects of Knowledge Sharing and Innovative Behavior on Job Satisfaction, Gachon University, Master Thesis, (2020)

[37] R. M. Baron, D. A. Kenny, The moderator-mediator variable distinction in social psychological research: Conceptual, strategic, and statistical considerations, Journal of personality and social psychology, (1986), Vol.51, No.6, pp.1173-1182, DOI: 10.1037//0022-3514.51.6.1173

[38] S. J. Lee, D. H. Ha, Effects of organizational culture on knowledge sharing and business performance, Journal of the Aviation Management Society of Korea, (2013), Vol.11, No.5, pp.19-40, UCI: G704-001900.2013.11.5.002

[39] I. O. Choi, J. H. Park, J. G. Sun, A study on the relationship between organizational culture and innovative behaviors of organizational members: the moderating effect of organizational trust and task conflict, The Journal of Business and Economics, (2011), Vol.27, No.3, pp.1-33, DOI: 10.22793/indinn.2011.27.3.001

[40] Z. G. Lin, The effect of professor perceived organization justice, organization trust and knowledge sharing on innovation behavior in China sports university, Keimyung University, Doctoral Dissertation, (2016) 